\title{
Identification of Somatosensory Compounds Contributing to Slipperiness and Thickness Perceptions in Canned Prunes (Prunus domestica)
}

Sagar Deshpande and Devin G. Peterson*

Department of Food Science and Technology, 317 Parker Food Science \& Technology Building, The Ohio State University, 2015 Fyffe Rd., Columbus, OH 43210

*Corresponding author: peterson.892@,osu.edu

317 Parker Food Science \& Technology Building, The Ohio State University

2015 Fyffe Rd.

Columbus, $\mathrm{OH} 43210$

PH: 614-688-2723

Email: peterson.892@osu.edu 


\section{Summary of Figures in Supporting Information}

Figure S1. MSMS spectra and proposed fragmentation pathway for 1-CQA.

Figure S2. MSMS spectra and proposed fragmentation pathway for 3-CQA.

Figure S3. MSMS spectra and proposed fragmentation pathway for 4-CQA.

Figure S4. MSMS spectra and proposed fragmentation pathway for VG.

This material is available free of charge via the Internet at http://pubs.acs.org. 


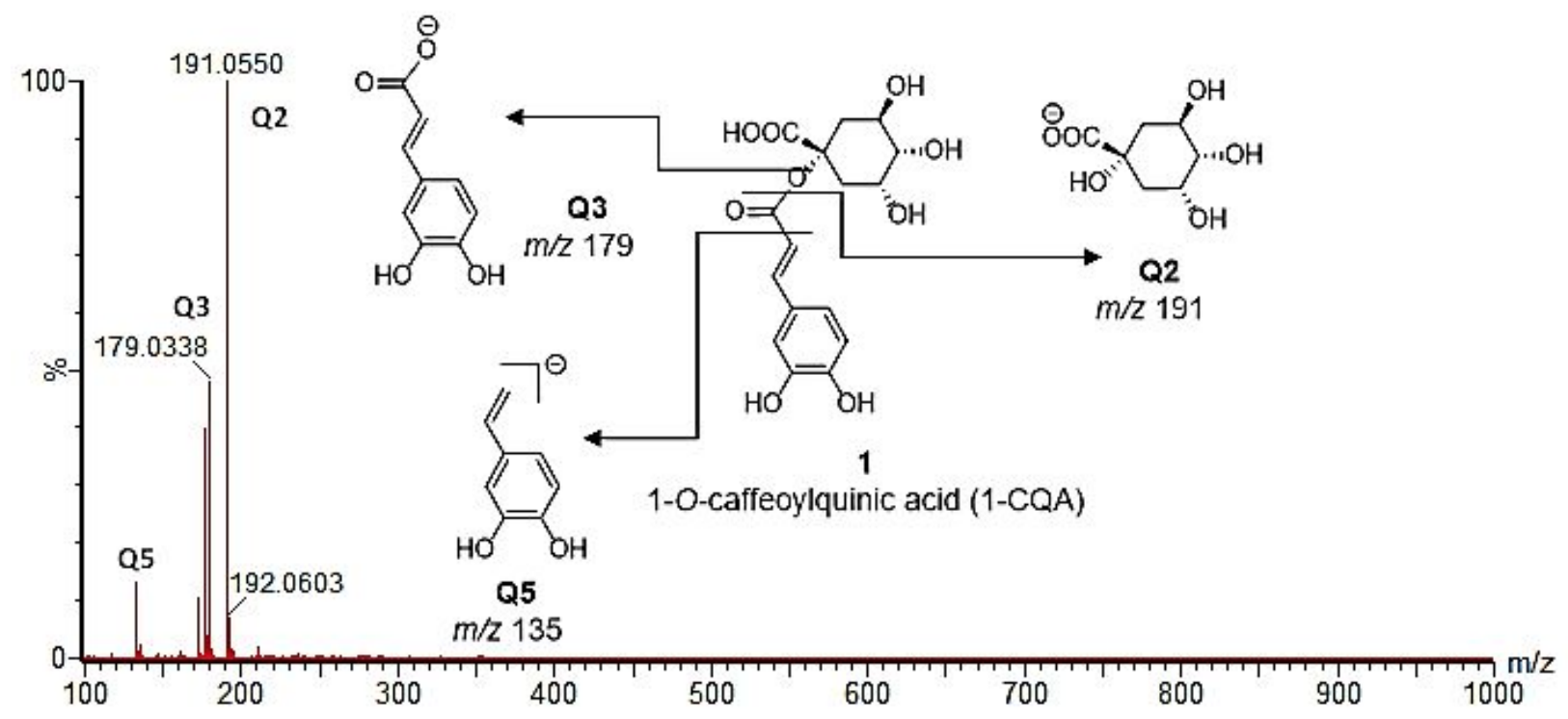

Figure S1.

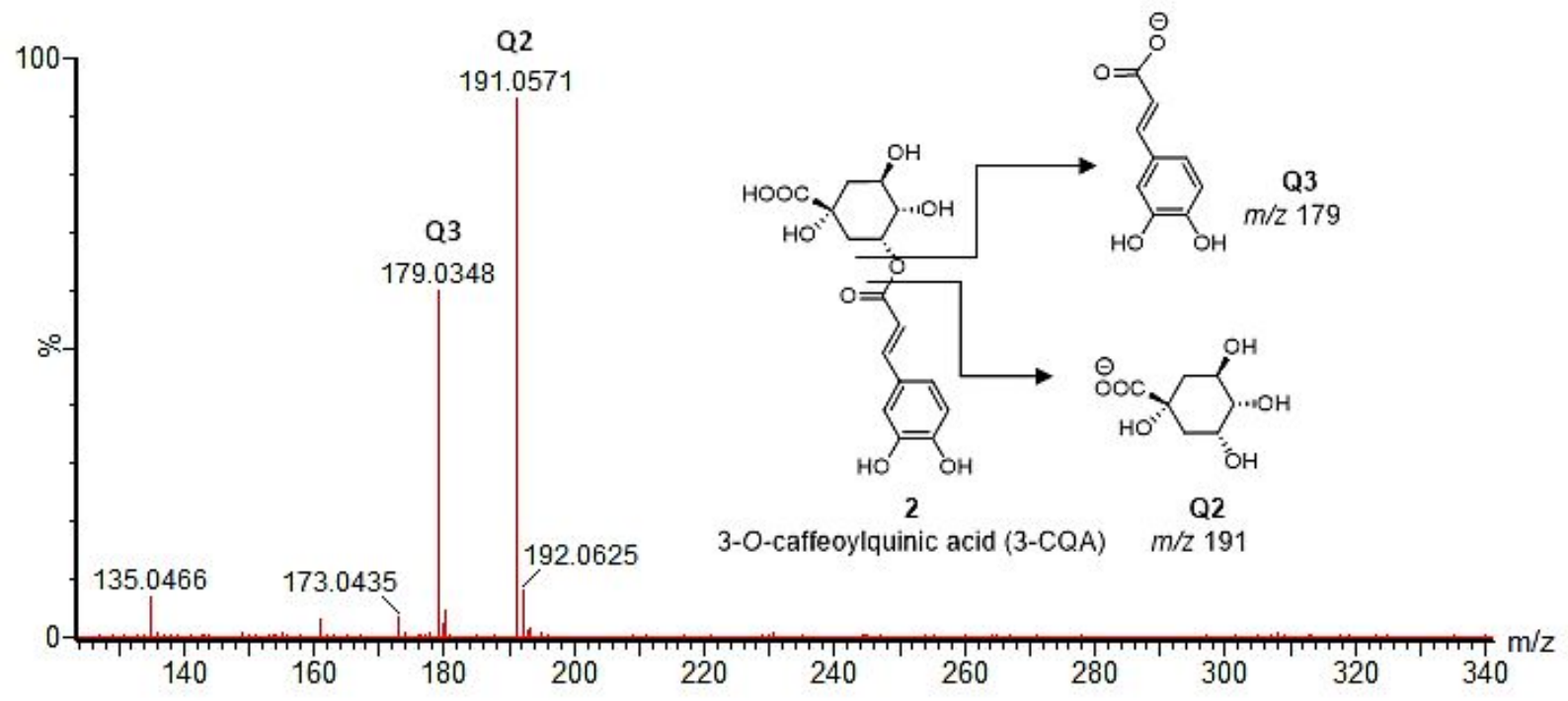

Figure S2. 


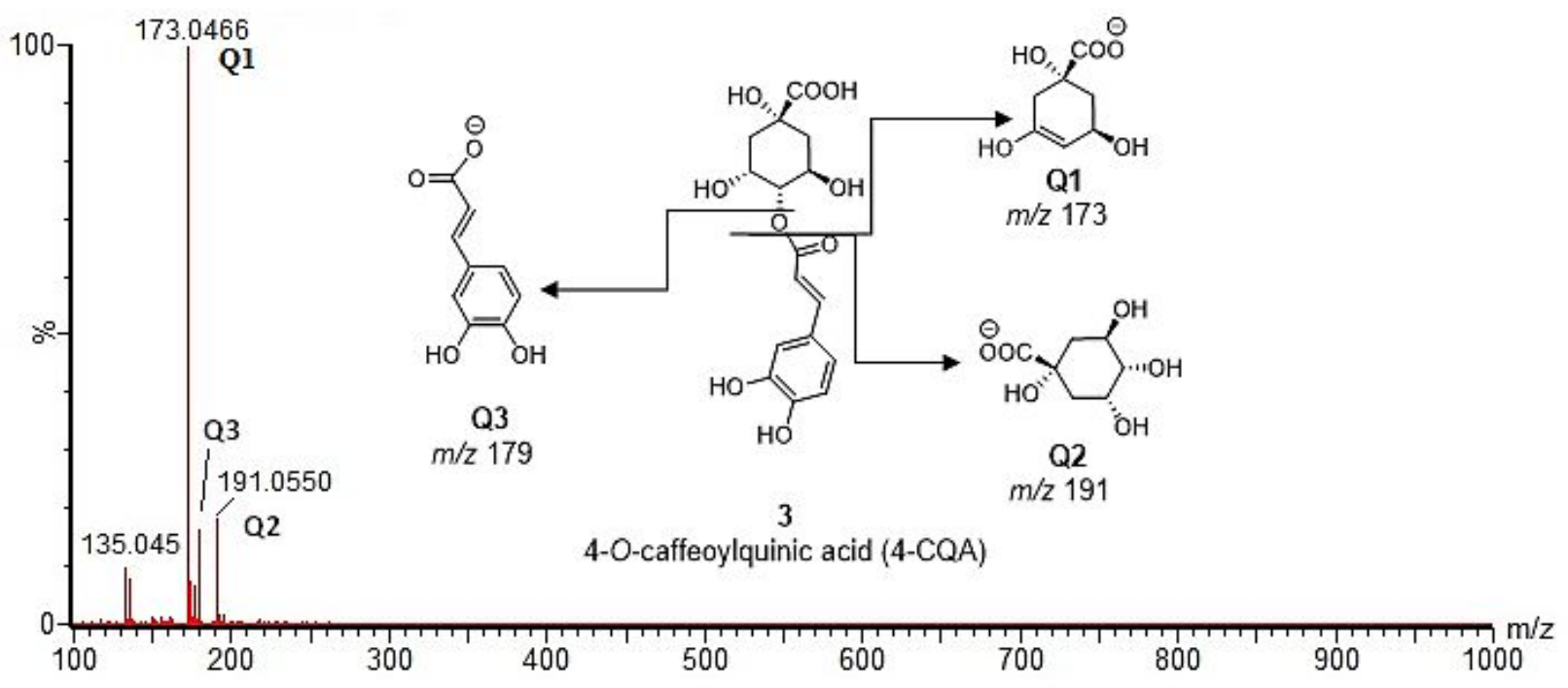

Figure S3.

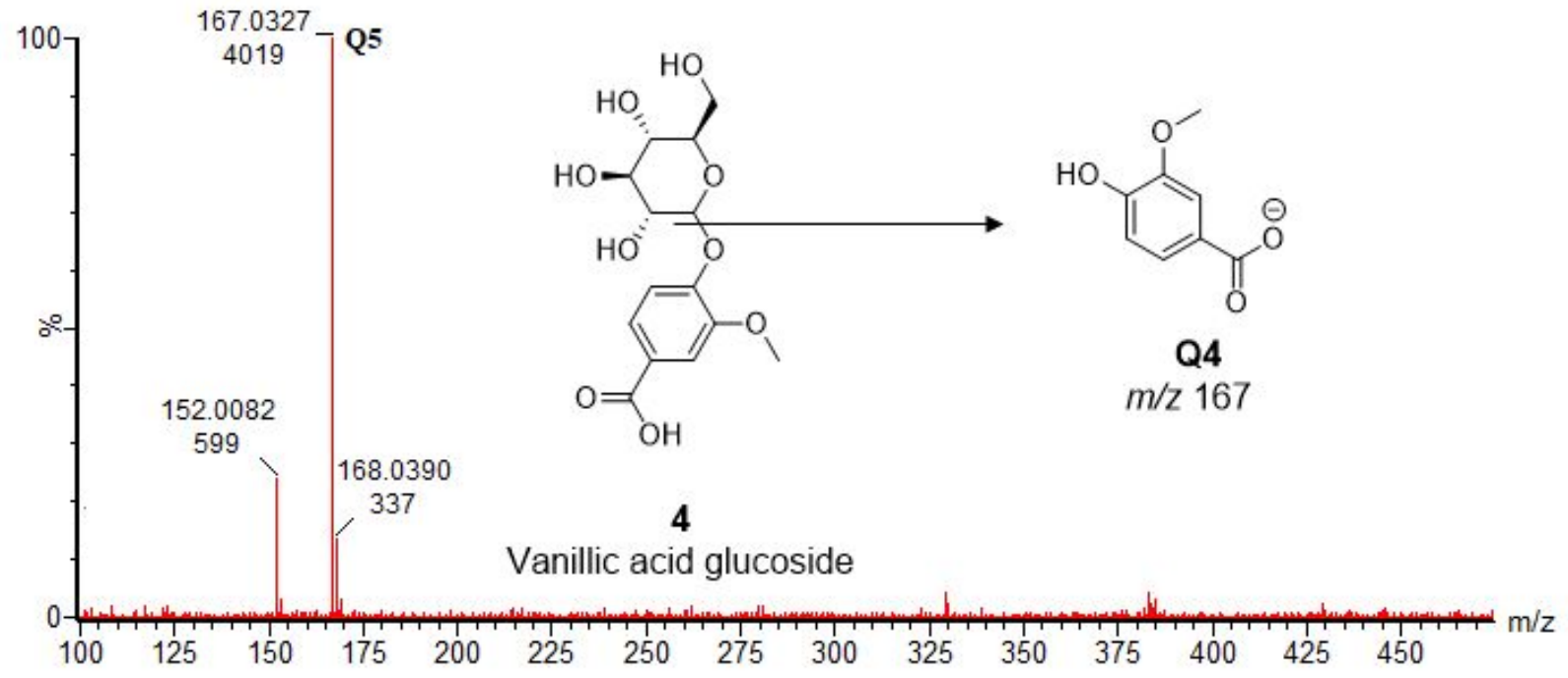

Figure S4. 